\title{
Retraction Note: An atomistic-based chemophysical environment for evaluating asphalt oxidation and antioxidants
}

\author{
Tongyan Pan • Lu Sun • Qifeng Yu
}

Published online: 4 September 2014

(C) Springer-Verlag Berlin Heidelberg 2014

Retraction to: J Mol Model (2012) 18:5113-5126

DOI 10.1007/s00894-012-1512-2

Upon request of the authors, this article is retracted because substantial parts were simultaneously submitted to and published in "A first-principles based chemophysical environment for studying lignins as an asphalt antioxidant" (Pan, T.; Construction and Building Materials, Volume 36, November 2012, Pages 654-664 DOI: 10.1016/j.conbuildmat.2012.06.012).

The online version of the original article can be found at http://dx.doi.org/ 10.1007/s00894-012-1512-2.

T. Pan $(\bowtie) \cdot$ L. Sun $\cdot$ Q. Yu

The Catholic University of America,

620 Michigan Avenue, N.E.,

Washington, DC 20064, USA

e-mail: pan@cua.edu

L. Sun

e-mail:sunl@cua.edu

Q. Yu

e-mail: yuq@cua.ed 